Research Article

\title{
Comparing the Coagulation Performance of Rice Husk, Cypress Leaves, and Eucalyptus Leaves Powders with That of Alum in Improving the Turbidity and pH of Some Local Water Sources in Bamenda, Cameroon
}

\author{
Cornelius Tsamo $\mathbb{D}^{1,2}$ Eric Fru Zama, ${ }^{1}$ Ngu Elton Yerima, \\ and Ajingne Nelson Mandela Fuh ${ }^{1}$ \\ ${ }^{1}$ Department of Agricultural and Environmental Engineering, College of Technology, University of Bamenda, P.O. Box 39, \\ Bambili, Bamenda, Cameroon \\ ${ }^{2}$ Department of Chemistry, Higher Teachers' Training College, University of Maroua, P.O. Box 55, Maroua, Cameroon \\ Correspondence should be addressed to Cornelius Tsamo; tcornelius73@yahoo.com
}

Received 9 July 2021; Revised 6 August 2021; Accepted 25 August 2021; Published 6 September 2021

Academic Editor: Abu Zahrim Zahrim

Copyright (c) 2021 Cornelius Tsamo et al. This is an open access article distributed under the Creative Commons Attribution License, which permits unrestricted use, distribution, and reproduction in any medium, provided the original work is properly cited.

\begin{abstract}
In this study, the efficiencies of the use of rice husk, cypress, and Eucalyptus leaves biocoagulants as alternative to alum as chemical coagulant in reducing turbidity and stabilizing the $\mathrm{pH}$ of slaughterhouse wastewater and three other local drinking water sources were investigated. Two systems were used: one involving individual coagulants and the second involving mix alum and biocoagulant with fixed alum dose of $0.05 \mathrm{~g}$ and varying amounts of each biocoagulant type ( 0.05 to $5 \mathrm{~g})$. Turbidity reduction, coagulation activity, and $\mathrm{pH}$ variation were used to characterize each system. Results show reduction in turbidity is higher in mixed coagulants than with individual coagulants. At $5 \mathrm{~g}$ each of alum, rice husk, cypress, and Eucalyptus leaves, the corresponding turbidity values, $8.3,13.6,14.5$, and $20.3 \mathrm{NTU}$, were obtained compared to 7.3 with 0.05 alum and $5 \mathrm{~g}$ rice husk mixture, 8.7 NTU with $0.05 \mathrm{~g}$ alum and $5 \mathrm{~g}$ cypress leaves mixture, and $16.1 \mathrm{NTU}$ with $0.05 \mathrm{~g}$ alum and $5 \mathrm{~g}$ Eucalyptus leaves mixture, for 37.3 NTU initial turbidity. The used biocoagulants individually show insignificant effect on the $\mathrm{pH}$ of coagulation-treated water. Alum has an insignificant effect up to $2 \mathrm{~g} .0 .05 \mathrm{~g}$ of each biocoagulant stabilizes the pH between 6.57 and 7.34 against 4.14 for alum. $0.05 \mathrm{~g}$ alum/ $0.05 \mathrm{~g}$ biocoagulant stabilized the $\mathrm{pH}$ of water between 6.32 and 7.41 . The coagulation activities for individual systems follow the order alum $>$ rice husk $>$ cypress $>$ Eucalyptus, and for mixed systems, alum/rice husk $>$ alum/cypress $>$ alum/Eucalyptus. Water with turbidity and $\mathrm{pH}$ values within the World Health Organization's guideline value of $<5$ NTU and 6.5-8.5, respectively, were obtained using studied low cost and locally available biocoagulants.
\end{abstract}

\section{Introduction}

It is generally said that water is life due to the fact that it is very essential for nearly all activities on Earth, such as agriculture, industries, domestic, and recreation [1]. The WHO (World Health Organization) estimates show that about $80 \%$ of all diseases and sicknesses in the world are due to inadequate sanitation, polluted water, or unavailability of water $[1,2]$. WHO reports that some 2 billion people worldwide use contaminated drinking water sources with rural communities mostly in developing countries not having access to safe drinking water [3]. This WHO estimate equally shows that 4 million children die in developing countries each year from waterborne diseases [1]. According to [4], the lack of good quality water is the most serious environmental concerns that developing countries are facing. Most regions of the world are on track to meet the target on drinking water quality [5]. Unfortunately, Sub-Saharan Africa is the main region lagging behind, most especially in the rural areas. Sub-Saharan Africa will not even meet the 
Millennium Development Goals sanitation target until 2076 with current rates of progress [5]. According to [6], "at any given time, about half the population in the developing world is suffering from one or more of the six main diseases (Diarrhea, Ascaris, Dracunculiasis, Hookworm, Schistosomiasis, and Trachoma) associated with water supply and sanitation."

Turbidity which describes the cloudiness of water caused by suspended particles such as clay and silts, chemical precipitates such as manganese and iron, and organic particles such as human and livestock wastes, plant debris, and organisms is used in the operational monitoring of control measures included in water safety as a recommended approach to managing drinking-water quality [7]. Turbidity generally does not represent a major public health risk [8]. Nonetheless, it may be an indication of the presence of pathogenic microorganisms and hazardous events throughout the water supply system, from catchment to point of use. Hence, the point of detection is very necessary in order to consider potential impacts. Source waters with elevated turbidity indicate pollution events in the catchment and can have negative effects on the performance of coagulation and clarification, filtration, and disinfection. For example, if turbidity targets for filtered water are not attained, then it may indicate firstly the presence of pathogens in drinking water and secondly high level of turbidity in distribution systems which may indicate detachment of biofilms and oxide scales or entry of external sources of contamination [8].

Turbidity reduction is therefore an essential step in water treatment processes either for large scale treatment plants, small communities, or households. In developing countries and most especially in rural areas without water treatment systems and who rely heavily on polluted water sources, such as rivers, small community water supply, small dams, ponds, and traditional wells, there may be a need to render the water safe for drinking at household level through turbidity reduction followed by sand filtration and then disinfection [9]. Turbidity reduction in water has been accomplished generally by using coagulation and flocculation processes. There are two main groups of coagulants used in coagulation: natural based, such as using plants (biocoagulant) and the chemical based, mainly alum, ferric chloride, and poly aluminum chloride (PAC) [10]. The cost of importing the chemical coagulants is very expensive for many developing countries resulting in using water of doubtful quality and with consequences on their health $[10,11]$. Other inconveniences in using the chemical coagulant include difficulties in disposing high volume of generated coagulant sludge, presence of residual aluminum in the treated water, reaction of aluminum with alkalinity present in the water leading to the big drop in the $\mathrm{pH}$ of water, and its low coagulating efficiency in cold water [11]. Alum compounds can trigger Alzheimer's disease as reported by $[10,11]$. Other studies have also reported that monomers of PAC and alum have neurotoxicity [10]. Faced with negative challenges of using chemical coagulants, researchers are interested in plantbased biocoagulants as alternative to chemical coagulants because they are biodegradable and nontoxic and hence safer to the environment and human $[10,12]$. Some studies have tested the use of the following biocoagulants in water turbidity reduction by coagulation: moringa, chickpea and avocado seed [10], Moringa oleifera, Jatropha curcas, chitosan, dragon fruit foliage [9, 11], acorn leaves, [12], Moringa oleifera, Cicer arietinum, and Dolichos lablab [13], Moringa oleifera seeds [14], aloe vera [15], and chestnuts [16]. All these report significant turbidity reductions with no secondary contamination.

From these studies, it can be seen that rice husk, cypress leaves, and Eucalyptus leaves have rarely been used as biocoagulants. These materials are so abundant locally at no cost. This study is therefore aimed at comparing the performances of rice husk, cypress leaves, and Eucalyptus leaves powders with that of alum in reducing the turbidity of some local water sources and maintaining the $\mathrm{pH}$ of the coagulated water within the WHO standard for drinking water. This is probably the first work using rice husk, cypress leaves, and Eucalyptus leaves as biocoagulants. The experiments were conducted in two parts. The first set of experiments involved the use of each biomass type and alum separately for each water sample and in the second set of experiments by varying the biomass quantity while keeping the amount of alum constant at $0.5 \mathrm{~g}$. Results of this study can make the water treatment process easier, cheap, and environmental friendly for community water projects as well as households with borehole and well waters.

\section{Materials and Methods}

2.1. Rice Husk, Cypress Leaves, Eucalyptus Leaves, and Alum Sampling, Treatment, and Characterization. Fresh leaves of cypress and Eucalyptus were harvested from a single tree type, respectively, in Bamenda. This town has mainly a tropical savannah climate which favours the growth of these trees. They are the main sources of wood for different applications in the town. Rice husk was collected from the local rice production company called Upper Nun Valley Development Authority (UNVDA). Collected leaves and rice husk were properly washed with distilled water till no colour was emitted and dried at $105^{\circ} \mathrm{C}$ for 24 hours using a laboratory dry oven (DHG 9101-1SA; SEARCHTECH Instrument). A locally kaolin made alum (Figure 1) used in this study was bought from a local market where it is used locally to extract snail flesh from its shell. The alum and dried leaves samples were each converted to powder forms by crushing, sieved through a pore size of $>0.5 \mathrm{~mm}$, and stored in airtight polyethylene bottles for usage.

The surface composition of the leaves and alum was determined using Fourier transform infrared spectroscopy (FTIR) (Nicolet iS5 iD7 ATR, Thermo scientific; USA).

2.2. Collection of the Water Samples. Raw water sample were obtained from four sites in Bamenda which are all main drinking water sources for the different concerned communities with tens of thousands of inhabitants. The slaughterhouse wastewater was also chosen because it is the largest slaughterhouse in Bamenda with the capacity of 


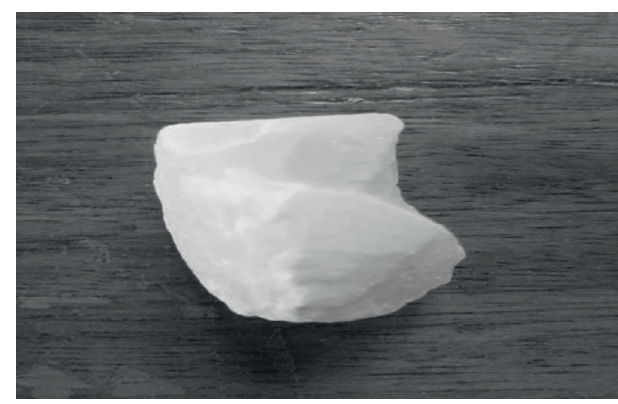

Figure 1: A sample of local kaolin obtained alum.

slaughtering about 24 cattle simultaneously, hence the high volume of wastewater generated which can recontaminate the meat:

(1) Mile 90 Njimafor in Bamenda II municipality as raw water before entering into the nearby screening cum sedimentation tank (designated as M90), coordinates: $05.934928^{\prime} \mathrm{N} 10.142552^{\prime} \mathrm{E}$.

(2) From a community well at Nitop V in Bamenda II municipality (designated as $\mathrm{CWN}$ ), coordinates: $05.960818^{\prime} \mathrm{N} 10.134913^{\prime} \mathrm{E}$.

(3) From the water storage tank of Bambili village community water (designated as BSW), coordinates: $05.994829^{\prime} \mathrm{N} 10.258627^{\prime} \mathrm{E}$.

(4) From mile 4 slaughterhouse in the Bamenda III municipality (designated as MSW). Samples here were collected on a Saturday at 7:00 am because it is the peak period of slaughter within the week, coordinates: $05.990715^{\prime} \mathrm{N} 10.187310 \mathrm{E}$.

Water samples were collected in polyethylene bottles (washed with detergent, then with distilled water, $2 \mathrm{M}$ nitric acid, then deionized water again, and finally with water from their various sample sources). Initial turbidity and $\mathrm{pH}$ were recorded on site. The samples were stored in a cooler at $4^{\circ} \mathrm{C}$ [17] and transported to the laboratory and coagulation studies performed immediately.

$\mathrm{pH}$ and turbidity readings were, respectively, measured using $\mathrm{PH}-981$ high accuracy pen-type $\mathrm{pH}$ meter with accuracy of \pm 0.1 and a Lovi-band 210 infrared turbid meter with the range of 0.01 to $1100 \mathrm{NTU}$.

The following initial turbidity values were obtained: 16.02, 18.0, 12.4, and 37.3 NTU for Mile 90 Njimafor raw water before entering into the nearby screening cum sedimentation tank, community well water, water storage tank of Bambili Village community water, and slaughterhouse wastewater, respectively, with corresponding $\mathrm{pH}$ of $6.5,6.45$, 6.7 , and 8.35 , respectively.

2.3. Coagulation Test. An adapted Jar test experiment (Figure 2) was used for this study. The experiments were conducted in two parts. The first set of experiments involved the use of each biomass type and alum separately for each water sample and in the second set of experiments by varying the biomass quantity while keeping the amount of alum constant at $0.05 \mathrm{~g}$. The aim was to minimize the effect of secondary contamination from alum while ensuring effective turbidity reduction and $\mathrm{pH}$ improvement of resulting water to within $\mathrm{WHO}$ standards for drinking water.

The coagulation was carried out in $500 \mathrm{~mL}$ beakers containing $100 \mathrm{~mL}$ of water sample under study. For the first set of experiments, varying doses of coagulant $(0.05,0.5,1,2$, 3.5 , and $5 \mathrm{~g}$ ) were added to the six beakers containing $100 \mathrm{~mL}$ of water for each water sample type. In the second set of experiments, the dose of each biomass was varied $(0.05,0.5$, $1,2,3.5$, and $5 \mathrm{~g}$ ) but that of alum was fixed at $0.05 \mathrm{~g}$.

In each case, mixing was done by stirring at $110 \mathrm{rpm}$ for 3 minutes and then reduced to $35 \mathrm{rpm}$ for 60 seconds, after which the Jar test apparatus was stopped and the mixture allowed to settle for a period of 1 hour. The supernatant was collected in separate beakers by decantation, and the $\mathrm{pH}$ and turbidity of the supernatants were measured.

The turbidity removal (TRE) of each coagulant type was calculated using the following equation [1]:

$$
\mathrm{TRE}=T_{0}-T \text {. }
$$

The coagulation activity or turbidity removal efficiency was calculated using the following equation [1]:

$$
\text { coagulation activity }=\left\{\frac{\left(T_{0}-T\right)}{T_{0}}\right\} * 100,
$$

where $T_{0}$ and $T$ represent the initial and final turbidity (or supernatant turbidity) values (NTU) of water, respectively.

\section{Results and Discussion}

3.1. FTIR Surface Characteristics of Alum, Rice Husk, Cypress, and Eucalyptus Coagulants. The FTIR spectra of rice husk, alum, cypress, and Eucalyptus leaves are presented in Figures 3(a)-3(d), respectively. The FTIR curve of rice husk (Figure 3(a)) shows the predominant band of the siloxane group $\mathrm{Si}-\mathrm{O}-\mathrm{Si}$ at about $1100 \mathrm{~cm}^{-1}$. This curve also shows the broadband between $2800 \mathrm{~cm}^{-1}$ and $3700 \mathrm{~cm}^{-1}$, which can be attributed to the $\mathrm{OH}$ groups and adsorbed water [18]. As seen from Figures 3(b)-3(d), these bands are also present in these samples, however, with different intensities. The intensity of the siloxane group, Si-O-Si from these spectra follows the order: alum $>$ rice husk $>$ cypress leaves $>$ Eucalyptus leaves. The coagulation performance of these samples as presented in Section 3.2 also follows this order. Hence, indicating the group $\mathrm{Si}-\mathrm{O}-\mathrm{Si}$ band is the main site responsible for the reactivity of these samples.

\subsection{Performance of Coagulants in Turbidity Reduction.} Water from four different sources and different initial turbidity values was tested.

Results of the coagulation of slaughter house wastewater (MSW) using individual coagulants are shown in Figure 4(a), while results obtained using varying amounts of biomass coagulants at fixed alum dosage are shown in Figure 4(b). It can be observed that there is significant reduction in turbidity with an increase in coagulant dose for the two systems evaluated. The reduction is more significant in mixed coagulants than with individual coagulants. From 


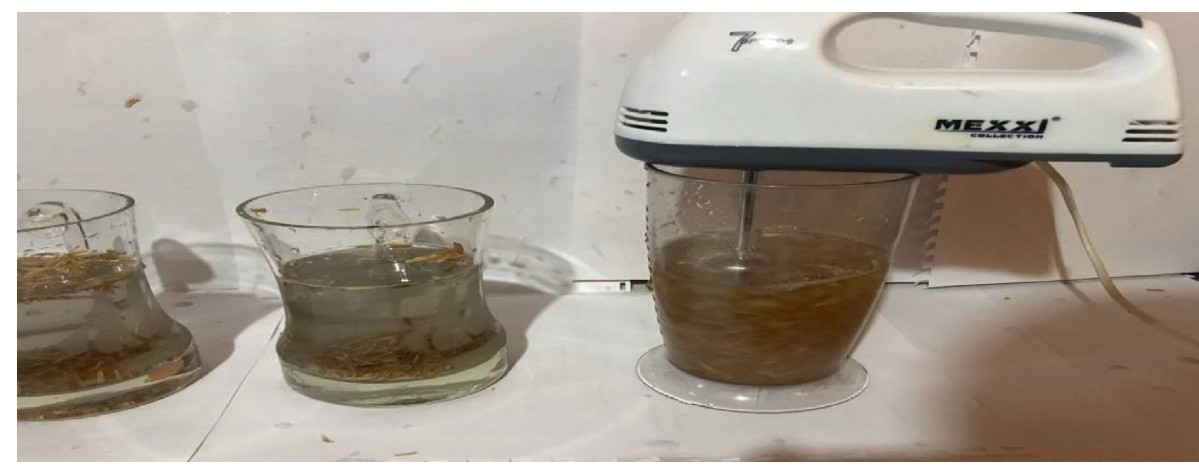

Figure 2: Adapted Jar test used in this study.

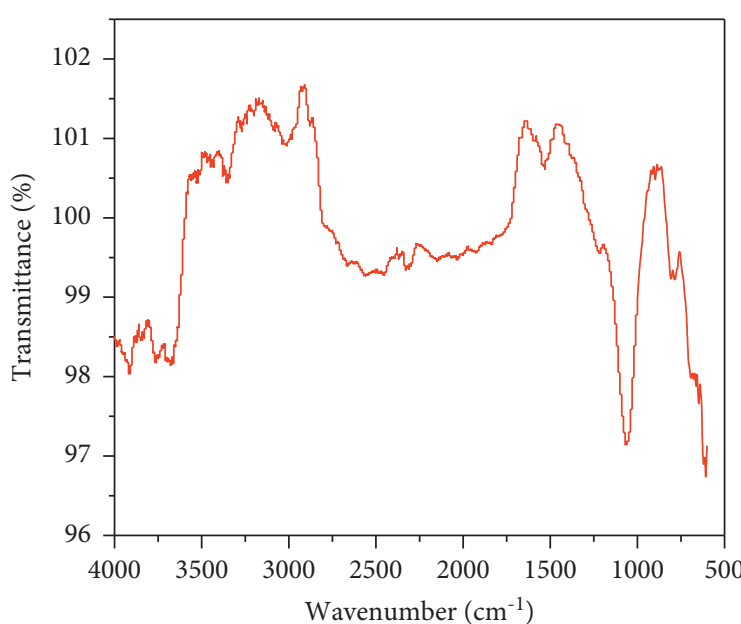

— Husk powder

(a)

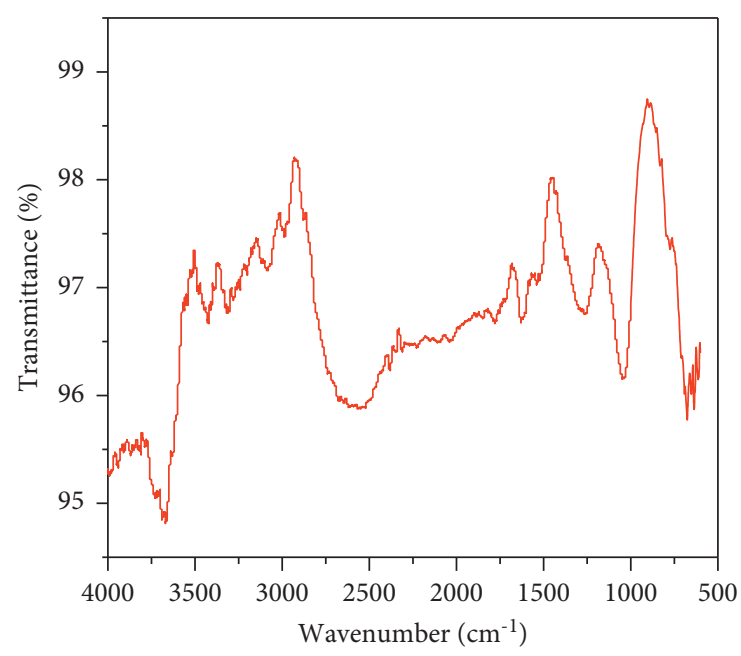

— Cypress

(c)

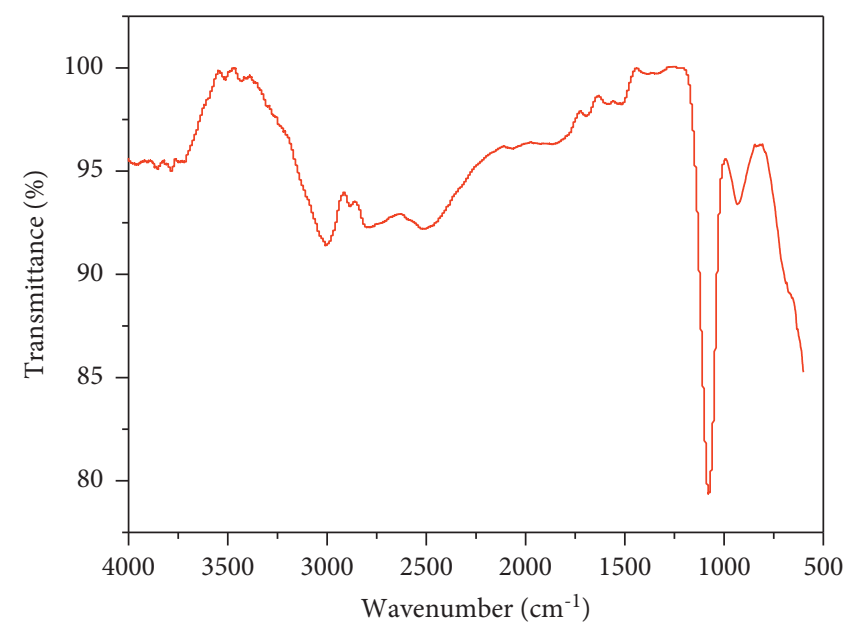

- Allum

(b)

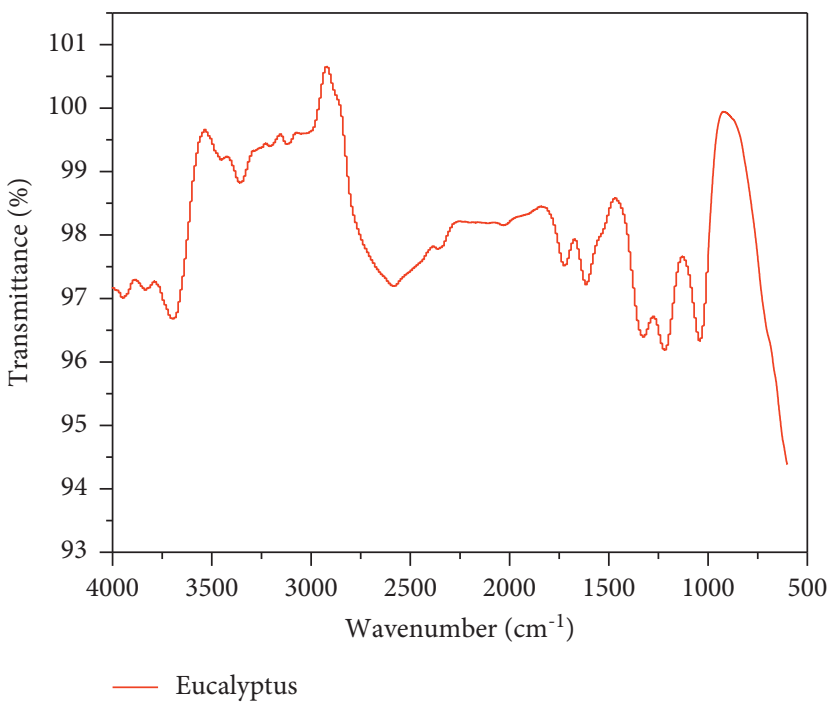

(d)

FIgURE 3: FTIR spectra of (a) rice husk, (b) alum, (c) cypress leaves, and (d) Eucalyptus leaves.

Figure 4(b), alum/rice husk reduced turbidity from 37.3 NTU to $10.6 \mathrm{NTU}$ with $0.05 \mathrm{~g}$ alum and $0.05 \mathrm{~g}$ rice husk mixture. This turbidity dropped to 7.3 with 0.05 alum and $5 \mathrm{~g}$ rice husk mixture. Corresponding turbidity reductions were observed for alum/cypress mixed coagulants, from 37.3 NTU to $11.4 \mathrm{NTU}$ with $0.05 \mathrm{~g}$ alum and $0.05 \mathrm{~g}$ cypress leaves 


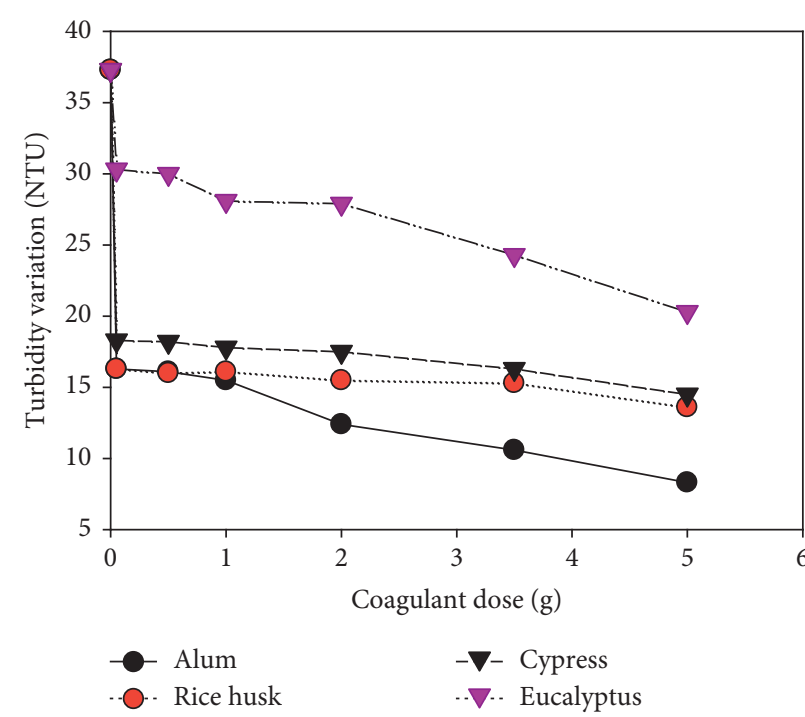

(a)

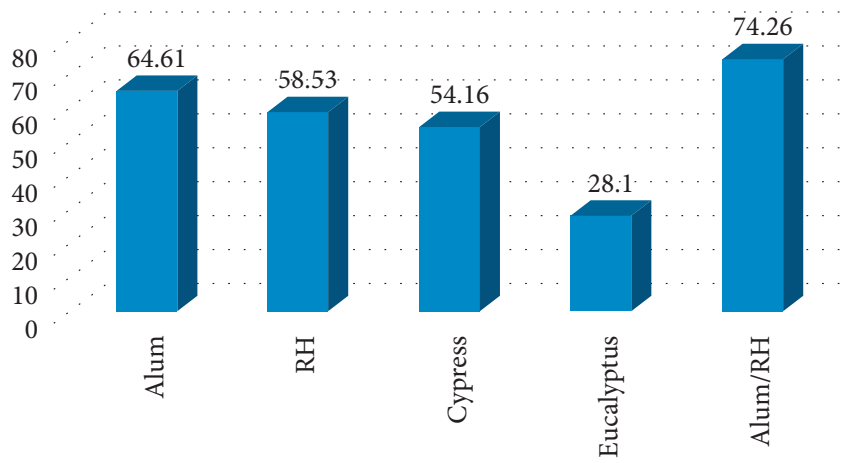

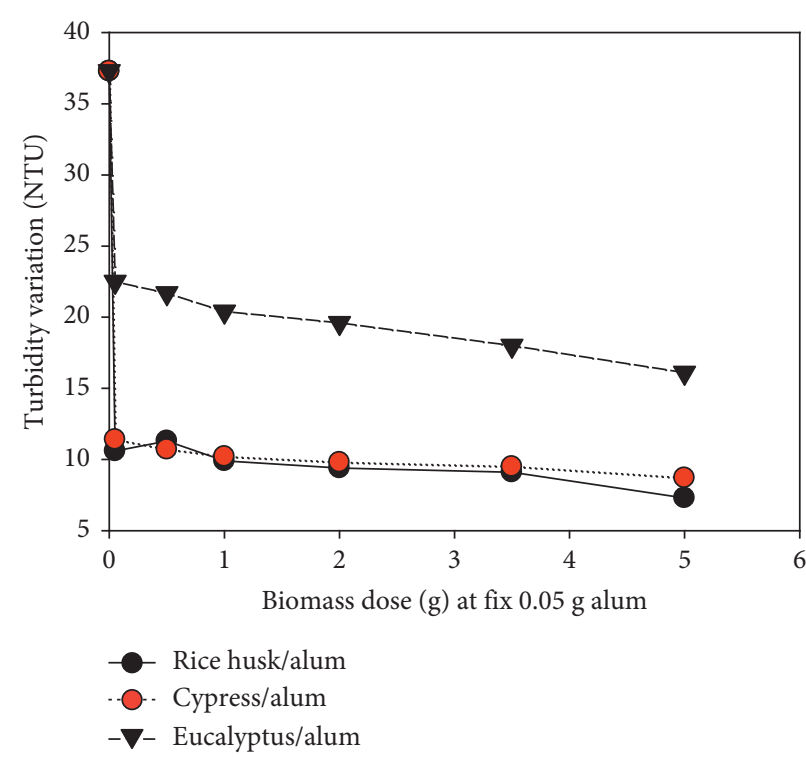

(b)

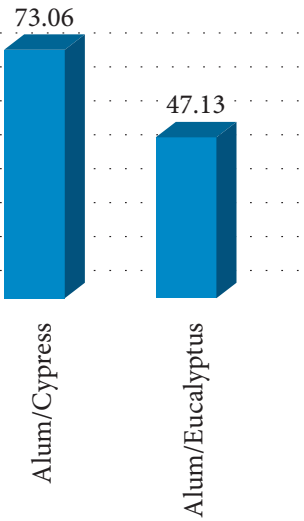

(c)

FIGURE 4: MSW variation of turbidity with (a) individual and (b) mixed coagulants and (c) coagulation activities (\%).

mixture and further to $8.7 \mathrm{NTU}$ with $0.05 \mathrm{~g}$ alum and $5 \mathrm{~g}$ cypress leaves mixture. Alum/Eucalyptus leaves mixture showed lesser turbidity reduction, with reductions from 37.3 NTU to $22.5 \mathrm{NTU}$ with $0.05 \mathrm{~g}$ alum and $0.05 \mathrm{~g}$ Eucalyptus leaves mixture and further to $16.1 \mathrm{NTU}$ with $0.05 \mathrm{~g}$ alum and $5 \mathrm{~g}$ Eucalyptus leaves mixture. While turbidity reductions were also observed in water samples using individual coagulants (Figure 4(a)), the reductions were less than those obtained with mixed coagulants. For example, with $5 \mathrm{~g}$ each of alum, rice husk, cypress, and Eucalyptus leaves, the following corresponding turbidity values $8.3,13.6,14.5$, and 20.3 NTU were obtained compared to 7.3 with 0.05 alum and $5 \mathrm{~g}$ rice husk mixture, 8.7 NTU with $0.05 \mathrm{~g}$ alum and $5 \mathrm{~g}$ cypress leaves mixture, and $16.1 \mathrm{NTU}$ with $0.05 \mathrm{~g}$ alum and $5 \mathrm{~g}$ Eucalyptus leaves mixture. The behaviour of the different coagulants was further determined by evaluating their respective coagulation activities using (2), and the results for MSW water sample are presented in Figure 4(c). As observed from Figure 4(c), the order of coagulation activity for individual system is alum $>$ rice husk $>$ cypress leaves $>$ Eucalyptus leaves, and for mixed systems, the order is alum/rice husk $>$ alum/cypress leaves $>$ alum/Eucalyptus leaves. According to [19], rice husk is a natural coagulant, which is effective in the reduction of water turbidity which is comparable with and can compete with alum in the water treatment process. The intensity of the siloxane group, Si-OSi from their FTIR spectra (Figure 3) follows the order: alum $>$ rice husk $>$ cypress leaves $>$ Eucalyptus leaves. The coagulation performance of these samples also follows this order, hence indicating the siloxane group, $\mathrm{Si}-\mathrm{O}-\mathrm{Si}$, is mainly responsible for the reactivity of these samples.

Opposite result trends were obtained for raw water before entering into the nearby screening cum sedimentation tank (M90) (Figure 5) initial turbidity of 16.0 NTU, well water (CWN) (Figure 6), initial turbidity of 18.0 NTU and water from community water storage tank (BSW) (Figure 7), and initial turbidity of 12.4 compared to slaughterhouse wastewater. In these water samples, turbidity values increased with increase coagulant dosage for both individual and mixed coagulants (Figures 5(a), 5(b), 6(a), 6(b), 7(a), and $7(b))$. This indicates that turbidity reduction in water samples depend on the composition of the said water 


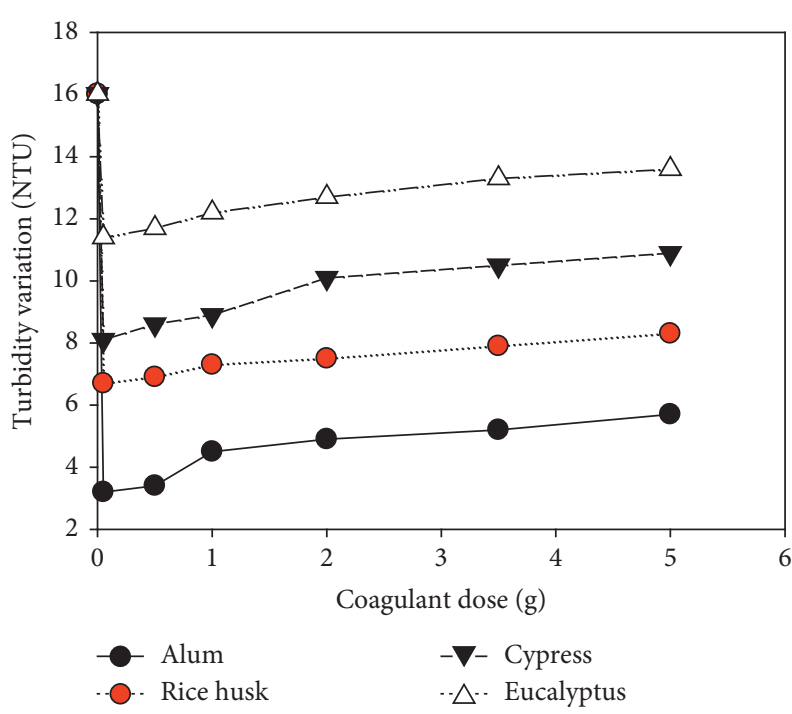

(a)

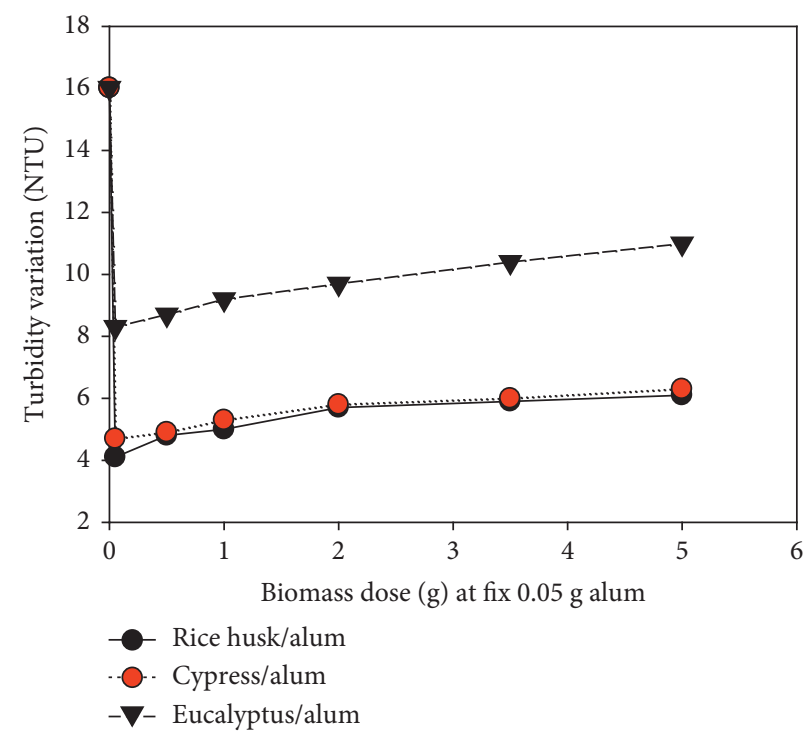

(b)

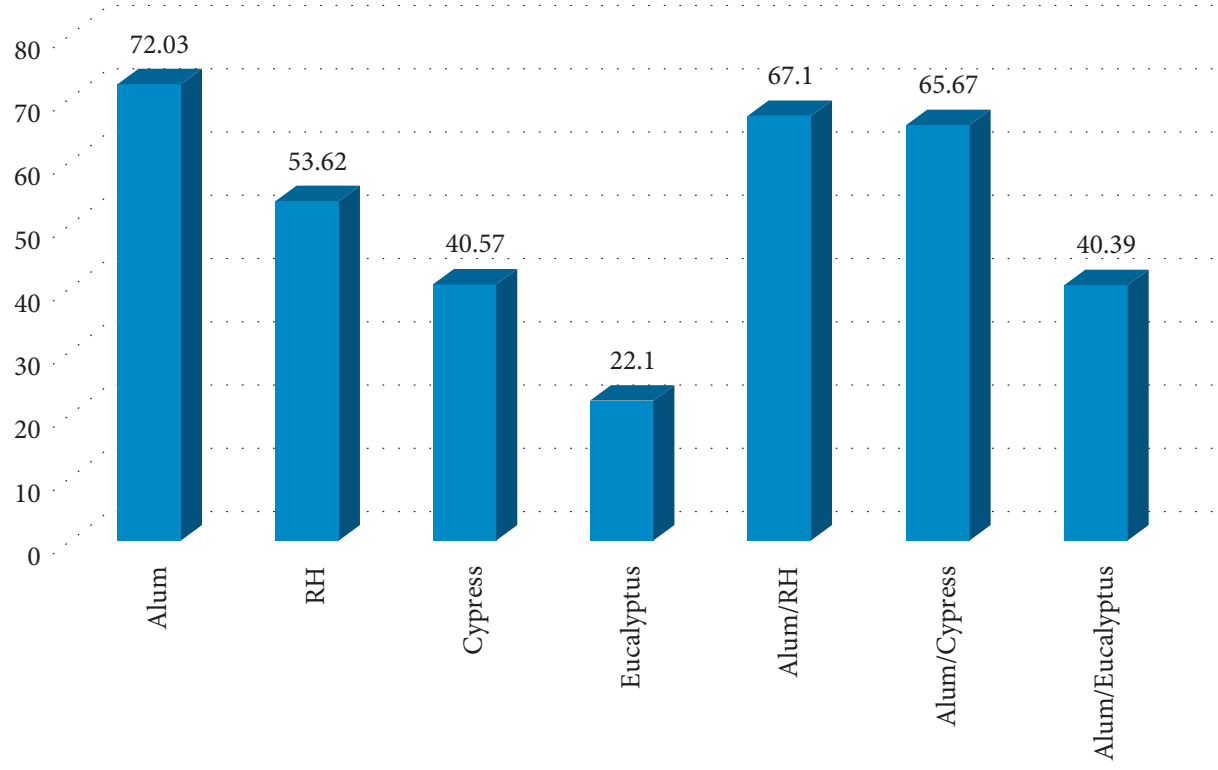

(c)

FIgURE 5: Variation of turbidity of M90 water with (a) individual, (b) mixed coagulants, and (c) coagulation activities (\%).

sample. Thus, $0.05 \mathrm{~g}$ of coagulant individually or $0.05 \mathrm{~g}$ each in a mixture gave maximum results. Patale and Pandya [20] used Mucilage extract of Coccinia indica fruit as coagulate flocculent for the treatment of turbid water samples and concluded that an optimum $0.4 \mathrm{mg} / \mathrm{L}$ gave best results. As observed from Figures 5(c), 6(c), and 7(c), the order of coagulation activity for individual and mixed systems was the same as for slaughter wastewater. From Figures 5(c), 6(c), and 7(c), the coagulation activity for alum (not mixed) in different water samples is of the order CWN water $>$ M90 water $>$ BSW water. However, for mixed coagulants, the order is M90 water $>\mathrm{CWN}$ water $>\mathrm{BSW}$ water. CWN water and M90 water samples have similar initial turbidity values of 18 and 16, respectively. This shows that high turbidity reduction is obtained in water with high turbidity compared to water with low turbidity. Increase in turbidity reduction with increase in initial turbidity results from an important driving force provided at higher initial turbidity necessary to overcome all mass transfer resistance [21, 22]. Deshmukh et al. [23] also observed that reduction in turbidity level depends on the raw water turbidity. Equally, the study in [24] treated turbid water from Guadiana River at Badajoz, Spain, and concluded that maximum turbidity reduction was found with high turbid raw water. Conversely, reduction in turbidity with increase coagulant dosage is due to the fact that coagulants hydrolyze in water to give a many different products among which the cations which are able to adsorb negatively charged particles. This process neutralizes their different charges, hence destabilizing the particles and resulting in particles aggregation $[25,26]$. With high 


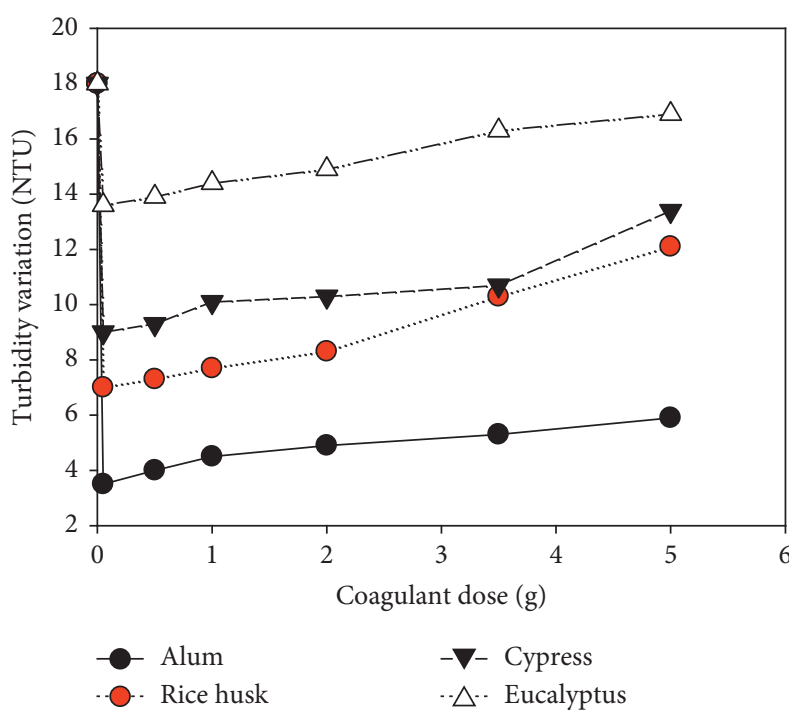

(a)

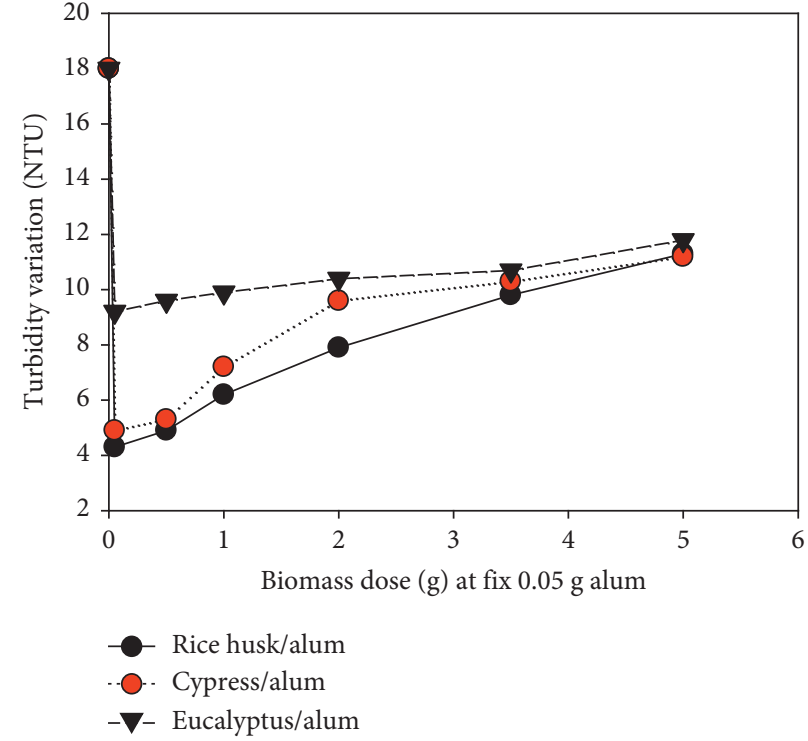

(b)

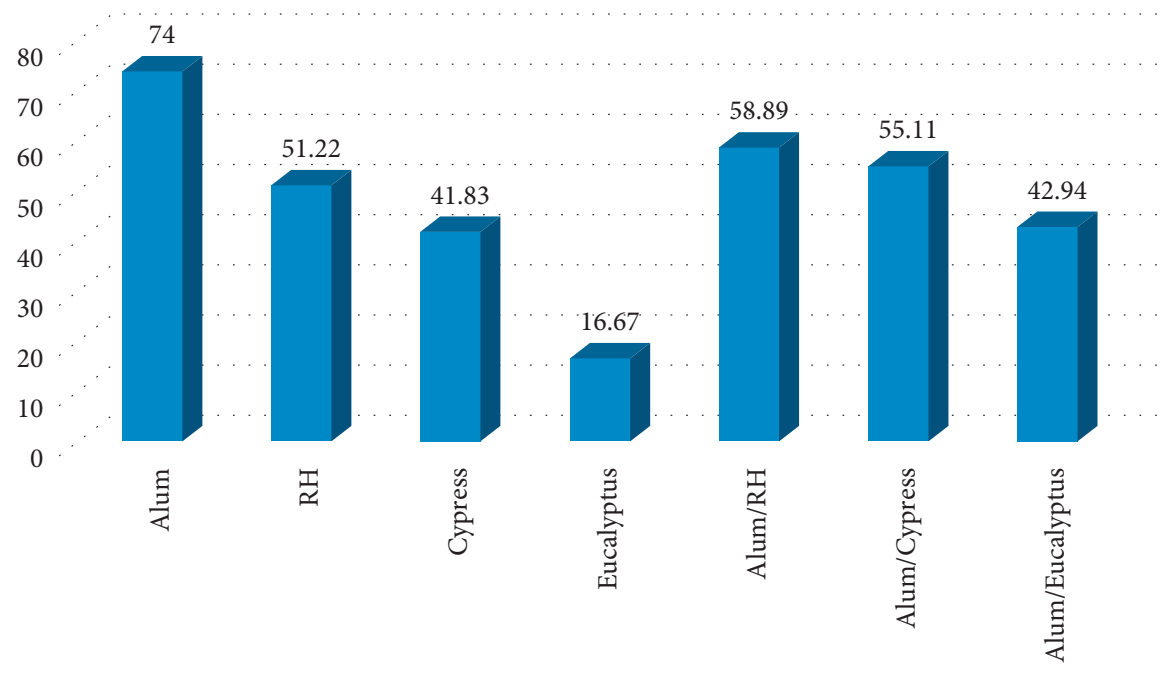

(c)

FIgURE 6: Variation of turbidity of well water with (a) individual, (b) mixed coagulants, and (c) coagulation activities (\%).

coagulant dosage charge, reversal occurs and particles begin to restabilize again leading to reduction in turbidity at high coagulant dosage.

3.3. Performance of Coagulants in Stabilizing pH. The variation of $\mathrm{pH}$ in each water sample treated with individual and mixed coagulants was monitored, and results are presented in Figure 8 for slaughter house wastewater (MSW), Figure 9 for raw water before entering into the nearby screening cum sedimentation tank (M90), Figure 10 for well water (CWN), and Figure 11 for water from community water storage tank (BSW).

The use of rice husk, cypress leaves, and Eucalyptus leaves individually as coagulant (in increasing dosage) shows insignificant effect on the $\mathrm{pH}$ of coagulated slaughterhouse water (Figure 8(a)). This is probably due to the fact that the biomass samples do not easily hydrolyze in water. Alum also has an insignificant effect with small amount of alum of up to $1 \mathrm{~g}$ alum. The resultant $\mathrm{pH}$ of treated water also exhibits different patterns for alum as compared to other coagulants. However, at high alum dosage, there is a very significant reduction in $\mathrm{pH}$ (Figure $8(\mathrm{a})$ ). At $2 \mathrm{~g}$ alum, the $\mathrm{pH}$ reduces to 7.15 , at $3.5 \mathrm{~g}$ it reduces to 6.03 , and at $5 \mathrm{~g}$ it drops to 4.13 . Malik [25] studied the use of alum coagulant in turbidity removal from muddy water and concluded that after coagulation with alum, the resultant $\mathrm{pH}$ was seen closer to 6 from an initial $\mathrm{pH}$ of 7 for $2 \mathrm{~g}$ alum. The alum used is aluminum rich kaolin which easily hydrolyze in water. This hydrolysis generally involves a sequential replacement of the water molecules by hydroxyl ions, which is equally considered as a progressive deprotonation of water molecules in 


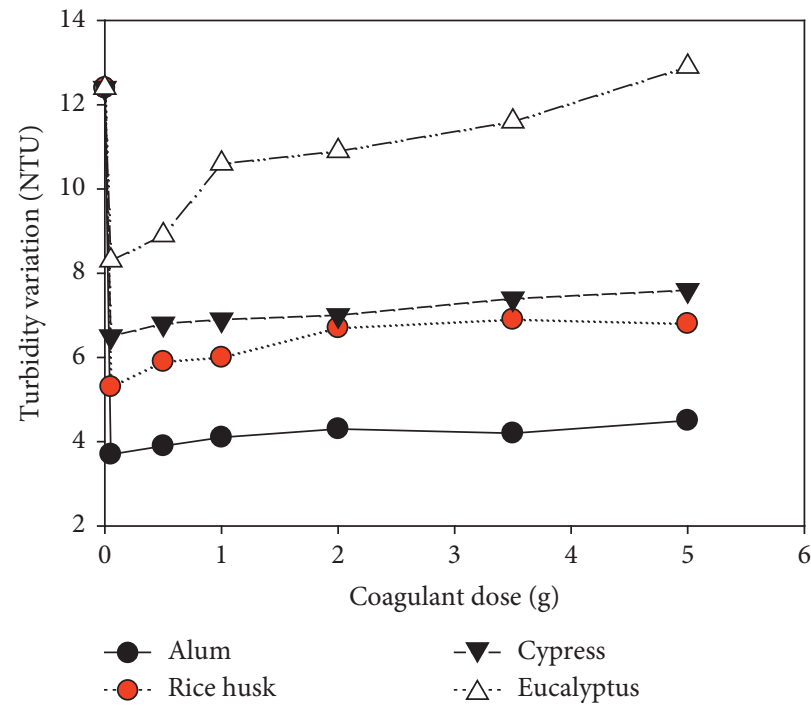

(a)

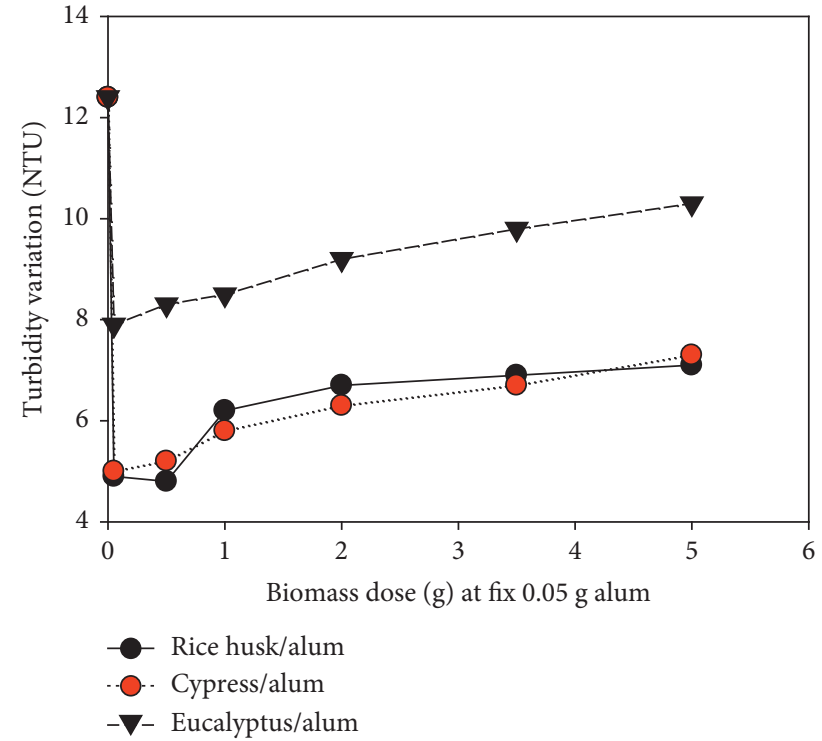

(b)

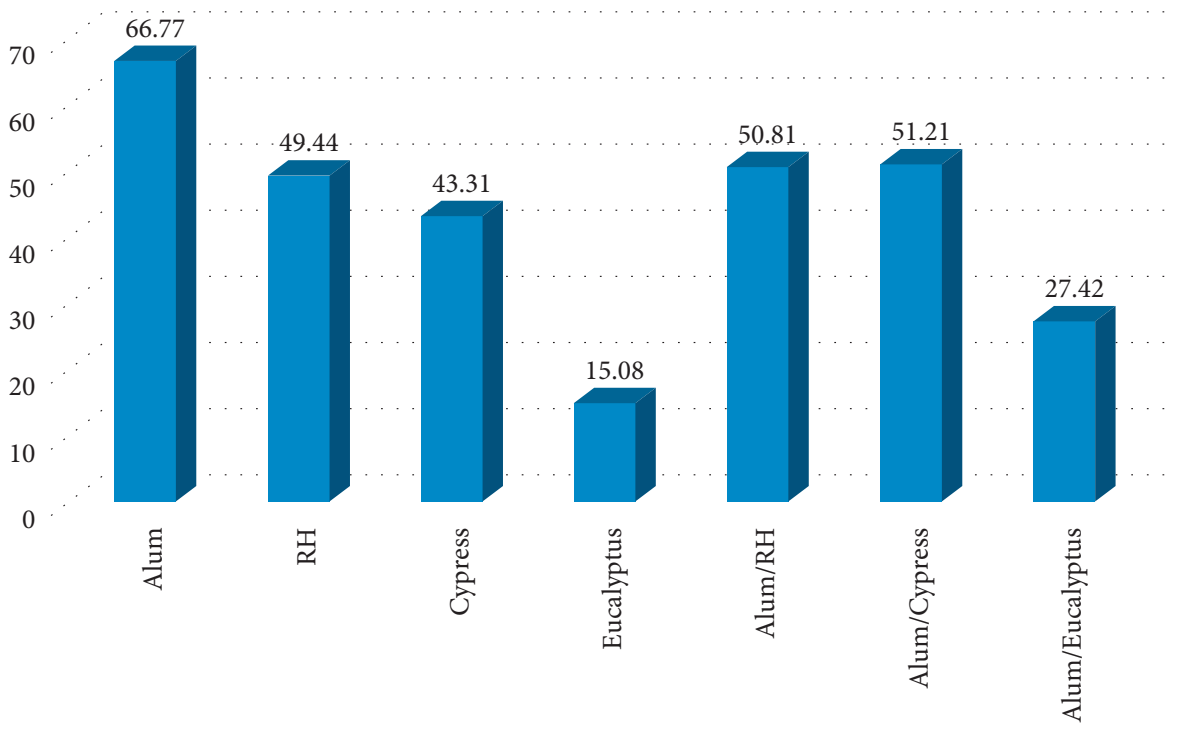

(c)

FIgURE 7: BSW variation of turbidity with (a) individual coagulants, (b) mixed coagulants, and (c) coagulation activities (\%).

the hydration shell [27]. Some steps involved in the hydrolysis are $\mathrm{Al}^{3+} \longrightarrow \mathrm{Al}(\mathrm{OH})^{2+} \longrightarrow \mathrm{Al}(\mathrm{OH})^{2+} \longrightarrow \mathrm{Al}(\mathrm{OH})$ ${ }^{3} \longrightarrow \mathrm{Al}(\mathrm{OH})^{4-}$. Each step here involves the loss of a proton, hence increasing the $\mathrm{pH}$ of water [27]. This trend in $\mathrm{H}^{+}$ generation explains why a $\mathrm{pH}$ of 4.13 was obtained with $5 \mathrm{~g}$ alum. From Figure 8(b) involving mixed coagulants, it is observed that with the mixture of $0.05 \mathrm{~g}$ alum and $0.05 \mathrm{~g}$ rice husk, cypress leaves, and Eucalyptus leaves each there is a significant reduction of $\mathrm{pH}$ from 8.35 to about 4.5 on average. However, with the increase in rice husk, cypress leaves, and Eucalyptus leaves dosage, there is an increase in $\mathrm{pH}$ attaining at $5 \mathrm{~g} 7.34$ for alum/rice husk, 6.21 for alum/ cypress, and 6.93 for alum/Eucalyptus. The fact that there was a significant drop in $\mathrm{pH}$ with small amounts alum/ biomass mixtures indicates that there is a strong reaction between alum and each biomass that liberate many protons from alum. But the biomass samples have hydroxyl groups on their surfaces (Figure 3) which can consume the generated protons from alum. This explains why with increase in biomass dose at constant alum, the $\mathrm{pH}$ turned toward neutral or water $\mathrm{pH}$ is determined by the properties of each biomass.

Similar $\mathrm{pH}$ trends to slaughterhouse wastewater using individual coagulants were obtained with other tested water samples but with slight variation (Figures 9(a), 10(a), and 11(a)). Opposite trends to slaughter house waste water were nonetheless obtained for mixed coagulants (Figures 9(b), 10(b), and 11(b)) at high coagulant dose. From Figure 9(a) (M90 Water), at $0.05 \mathrm{~g}$ coagulant, the $\mathrm{pH}$ changed from initial value of 6.5 to $4.15,7.49,7.33$, and 6.57 for alum, rice 


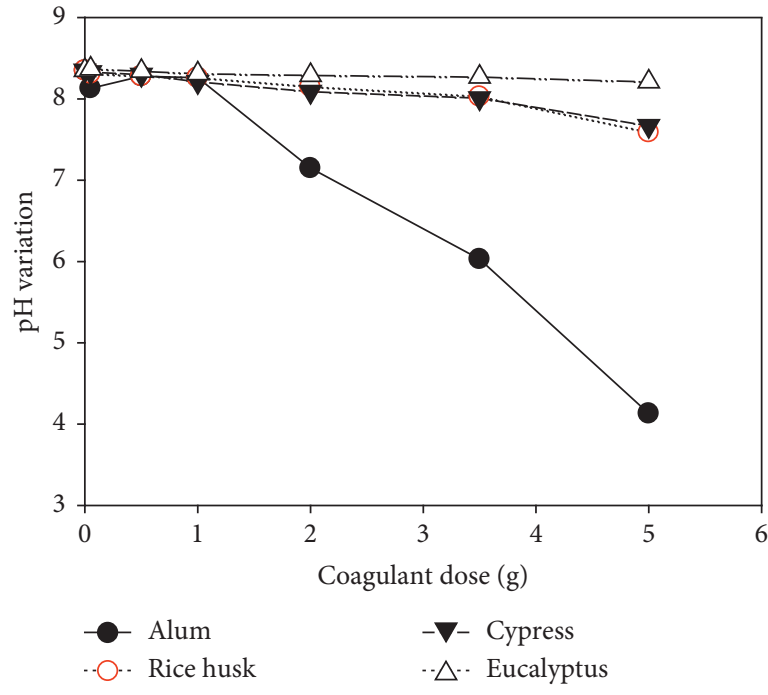

(a)

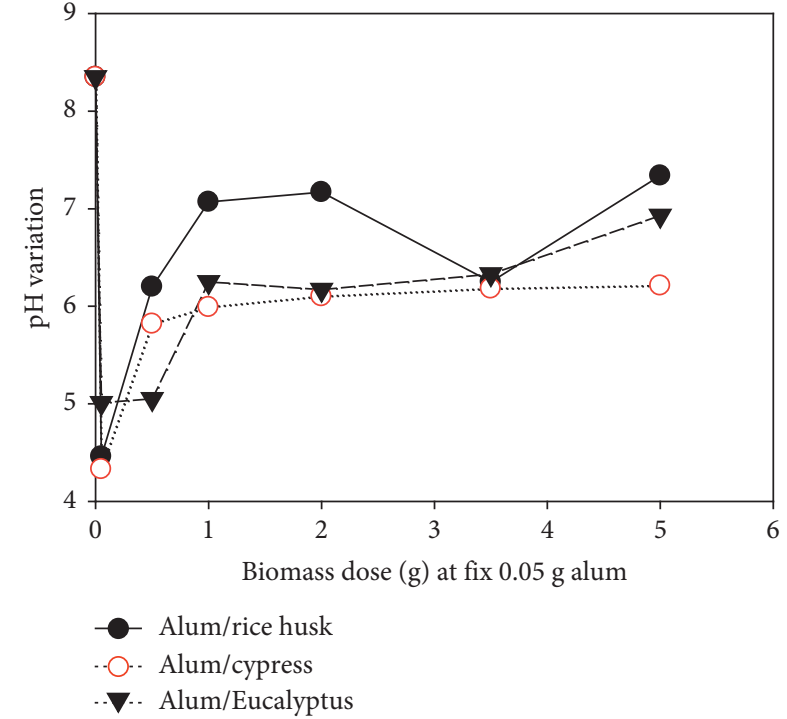

(b)

FIgURE 8: Variation of $\mathrm{pH}$ in MSW with (a) individual and (b) mixed coagulants.

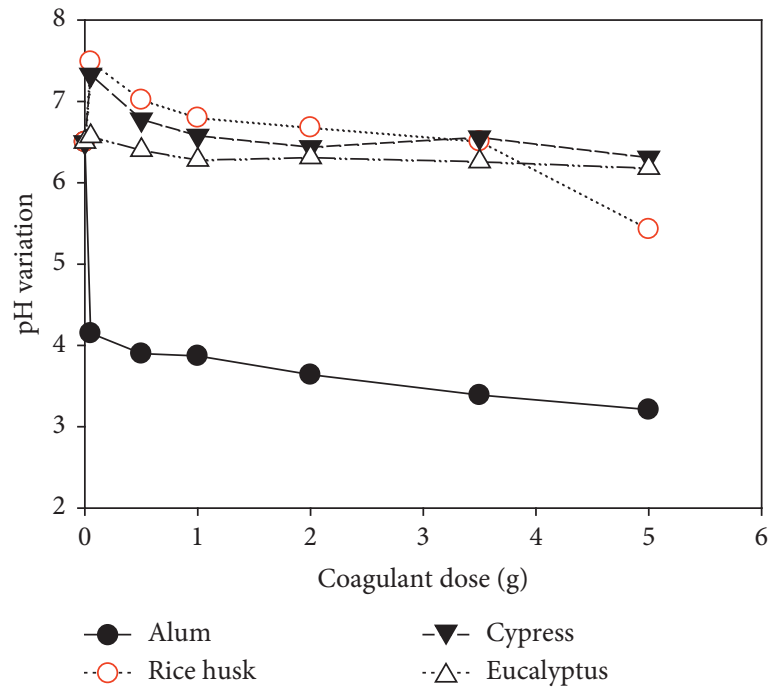

(a)

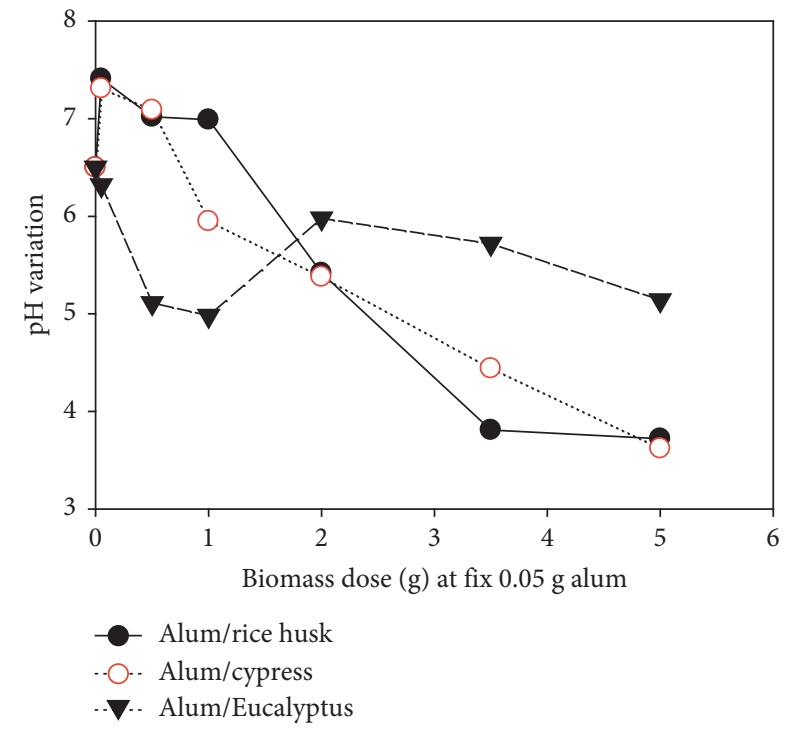

(b)

FIgURE 9: Variation of $\mathrm{pH}$ in M90 water with (a) individual and (b) mixed coagulants.

husk, cypress leaves, and Eucalyptus leaves, respectively. It subsequently reduced to $3.21,5.43,6.31$, and 6.81 at $5 \mathrm{~g}$ of alum, rice husk, cypress leaves, and Eucalyptus leaves each, respectively. Meanwhile, for mixed coagulants, $\mathrm{pH}$ changed from initial value of 6.5 to $7.41,7.31$ and 6.32 for $0.05 \mathrm{~g}$ alum/ $0.05 \mathrm{~g}$ rice husk, $0.05 \mathrm{~g}$ alum $/ 0.05 \mathrm{~g}$ cypress leaves, and $0.05 \mathrm{~g}$ alum $/ 0.05 \mathrm{~g}$ Eucalyptus leaves, respectively. These $\mathrm{pH}$ values for mixed coagulants reduced to $3.72,3.62$, and 5.41 for $0.05 \mathrm{~g}$ alum $/ 5 \mathrm{~g}$ rice husk, $0.05 \mathrm{~g}$ alum $/ 5 \mathrm{~g}$ cypress leaves, and $0.05 \mathrm{~g}$ alum $/ 5 \mathrm{~g}$ Eucalyptus leaves, respectively. These trends were the same but different in magnitude to well water
(Figures 10(a) and 10(b)) and BSW water (Figures 11(a) and 11(b)) samples.

The variation in $\mathrm{pH}$ results trends between slaughterhouse wastewater and other tested samples shows that the composition of the water determines the acid behaviour of the material use. The fact that eucalyptus seems to show more $\mathrm{pH}$ stability is normal as viewed from its surface properties given by FTIR results (Figure 3(d)). The surface properties of alum and biomasses are dominated by the Si$\mathrm{O}-\mathrm{Si}$ in the order alum $>$ rice husk $>$ cypress leaves $>$ Eucalyptus leaves. 


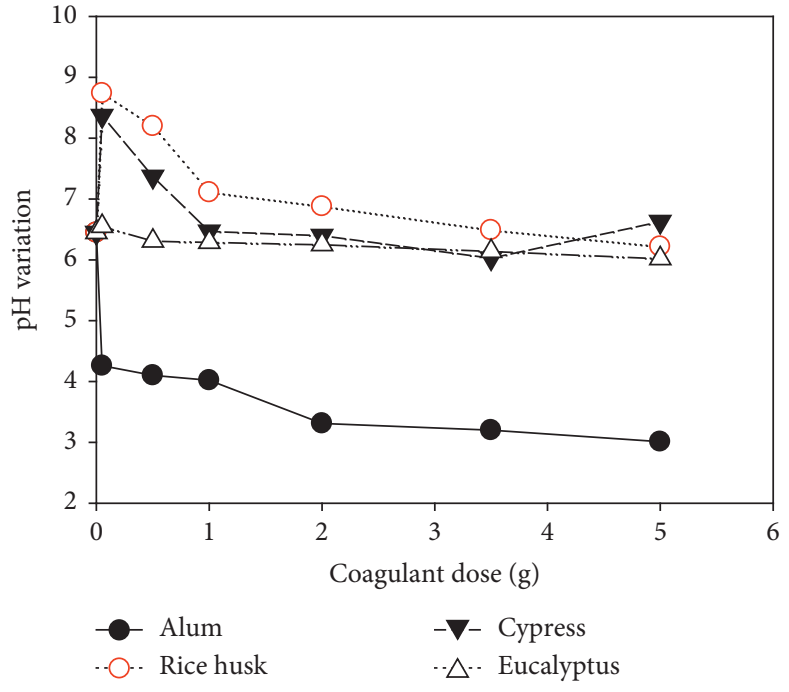

(a)

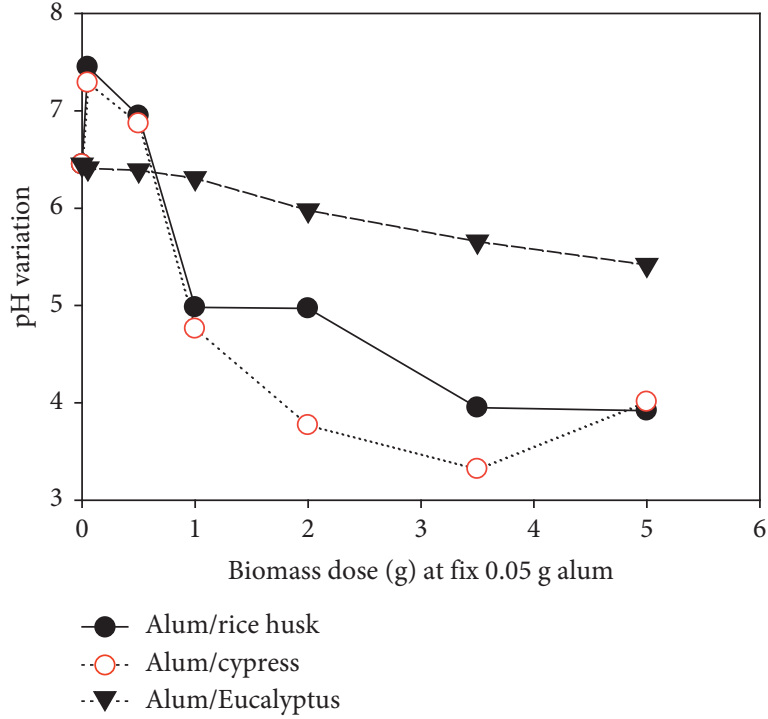

(b)

FIGURE 10: Variation of $\mathrm{pH}$ in well water with (a) individual and (b) mixed coagulants.

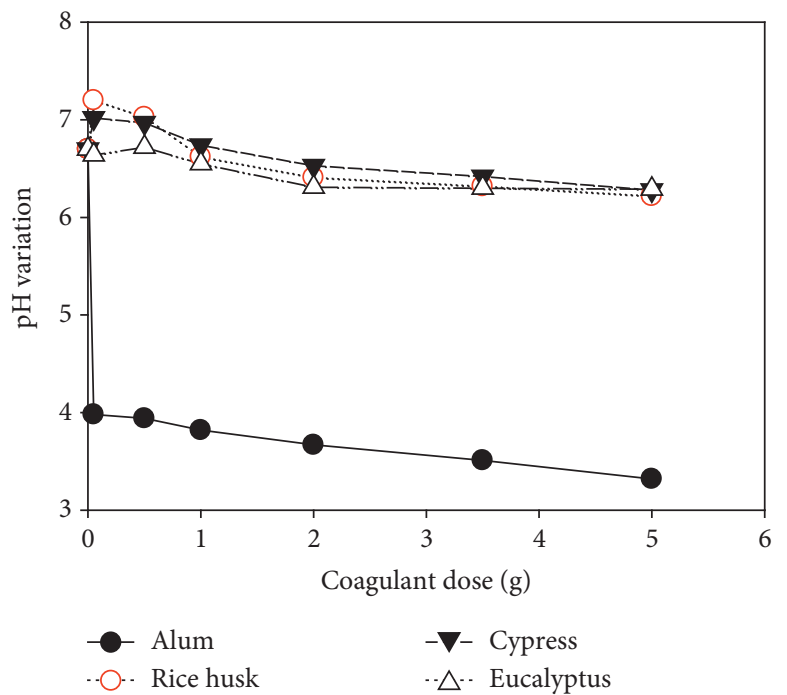

(a)

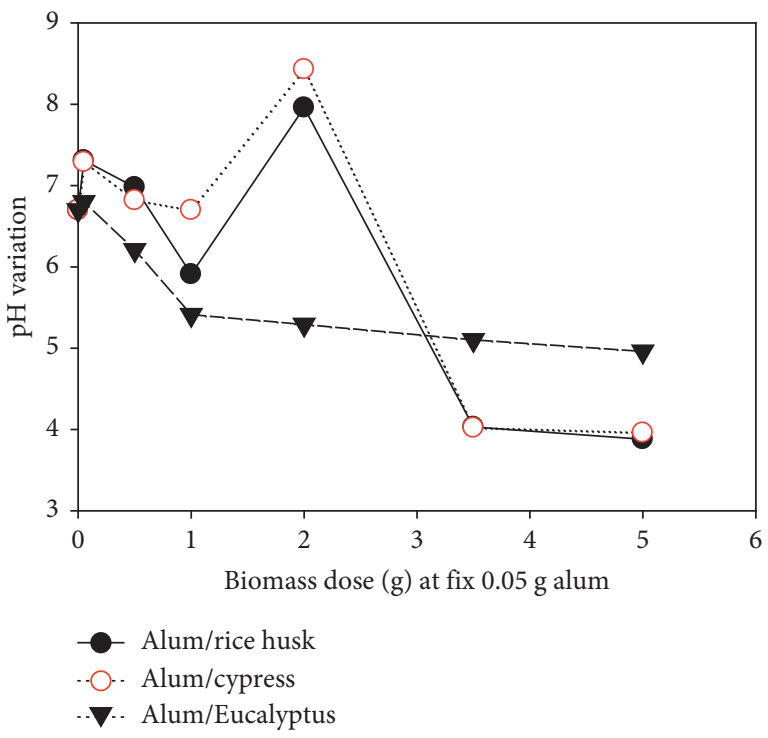

(b)

FIGURE 11: BSW variation of $\mathrm{pH}$ in BSW water with (a) individual coagulants and (b) mixed coagulants.

\section{Conclusion}

The efficiencies of rice husk, cypress, and Eucalyptus leaves as biocoagulants and a local kaolin obtained alum as chemical coagulant in reducing turbidity and stabilizing the $\mathrm{pH}$ of slaughterhouse wastewater and three other local drinking water sources were investigated. Results obtained showed that there is significant reduction in turbidity with an increase in coagulant dose for the two systems evaluated. The reduction is more significant in mixed coagulants than with individual coagulants. The findings of this work also show that high turbidity reduction is obtained in water with high turbidity than water with low turbidity. Equally, the composition of the water influences coagulation performance. The intensity of the siloxane group, Si-O-Si, from FTIR spectra follows the order alum $>$ rice husk $>$ cypress leaves $>$ Eucalyptus leaves. Thus, coagulation performance of these samples also follows this order, hence indicating the siloxane group, $\mathrm{Si}-\mathrm{O}-\mathrm{Si}$, is mainly responsible for the reactivity of these samples. The objective of using biocoagulants individually or mixed with alum in obtaining treated water with turbidity and $\mathrm{pH}$ values within the World 
Health Organization's guideline value of 5 NTU and 6.5-8.5, respectively, was therefore achieved in this study under different tested process conditions. The tested biocoagulants highly abundant and low cost can substantially reduce use of chemical coagulant in water treatment in developing countries, hence reducing secondary contamination and water treatment cost as well as protecting the environment through easy recycling of the bio coagulant.

\section{Data Availability}

The data used in plotting the different turbidity and $\mathrm{pH}$ curves are available and can be provided on request.

\section{Conflicts of Interest}

The authors declare no conflicts of interest.

\section{References}

[1] H. D. Beyene, T. D. Hailegebrial, and W. B. Dirersa, "Investigation of coagulation activity of cactus powder in water treatment," Journal of Applied Chemistry, vol. 2016, Article ID 7815903, 9 pages, 2016.

[2] C. Cornelius Tsamo, D. S. Djibrine Sali Meali, and H. T. Hippolyte Todou Assaouka, "Studying the impact of anions pre-generated iron corrosion products on the efficiency of contaminant removal in $\mathrm{Fe}_{0} / \mathrm{H}_{2} \mathrm{O}$ systems," Journal of Environmental Science and Engineering B, vol. 7, no. 1, pp. 1-10, 2018.

[3] WHO, "Drinking-water: key facts," 2019, https://www.who. int/news-room/fact-sheets/detail/drinking-water.

[4] A. Markandya, World Bank, and University of Bath, Water Quality Issues in Developing Countries, Contribution to a Volume on Essays in Environment and Development, J. Stiglitz, Ed., pp. 1-33, World Bank and University of Bath, Washington, DC, USA, 2004.

[5] Bureau of Economic Growth, Agriculture, and Trade, Bureau of Oceans, Environment, and Science, Addressing Water Challenges in the Developing World: A Framework for Action, 2009, https://reliefweb.int/sites/reliefweb.int/files/ resources/F619FB3C75EA4FEF492576F8000425CDFramework_for_Action.pdf.

[6] A. Gadgil, "Drinking water in developing countries," Annual Review of Energy and the Environment, vol. 23, no. 1, pp. 253-286, 1998.

[7] WHO, Guidelines for Drinking-Water Quality, World Health Organization, Geneva, Switzerland, 2017, http://www.who. int/water_sanitation_health/water-quality/guidelines/en/, Fourth edition.

[8] WHO, Water Quality and Health-Review of Turbidity: Information for Regulators and Water Suppliers, WHO, Geneva, Switzerland, 2017.

[9] A. Soros, J. E. Amburgey, C. E. Stauber, M. D. Sobsey, and L. M. Casanova, "Turbidity reduction in drinking water by coagulation-flocculation with chitosan polymers," Journal of Water and Health, vol. 17, no. 2, pp. 204-218, 2019.

[10] R. S. Putra, R. Y. Amri, and M. Ayu, "Turbidity removal of synthetic wastewater using bio coagulants based on protein and tannin," in Proceedings of the 5th International Symposium on Current Progress in Mathematics and Sciences (ISCPMS2019) AIP Conference Proceedings 2242, Depok, Indonesia, 2020.
[11] N. Khodapanah, I. S. Ahamad, and A. Idris, "Potential of using bio-coagulants indigenous to Malaysia for surface water clarification," Research Journal of Chemistry and Environment, vol. 17, no. 9, 2013.

[12] A. Benalia, K. Derbal, A. Panico, and F. Pirozzi, "Use of acorn leaves as a natural coagulant in a drinking water treatment plant," Water, vol. 11, no. 1, pp. 57-12, 2019.

[13] M. Asrafuzzaman, A. N. M. Fakhruddin, and M. A. Hossain, "Reduction of turbidity of water using locally available natural coagulants," ISRN Microbiology, vol. 2011, Article ID 632189, 6 pages, 2011.

[14] H. T. Nhut, N. T. Q. Hung, B. Q. Lap et al., "Use of Moringa oleifera seeds powder as bio-coagulants for the surface water treatment," International Journal of Environmental Science and Technology, vol. 18, no. 8, pp. 2173-2180, 2021.

[15] H. N. Kim, S. L. Walker, and S. A. Bradford, "Macromolecule mediated transport and retention of Escherichia coli O157 : H7 in saturated porous media, water research in saturated porous media," Water Research, vol. 44, no. 4, pp. 1082-1093, 2010.

[16] M. S'ciban, M. Klasnja, M. Antov, and B. Skrbi'c, "Removal of water turbidity by natural coagulants obtained from chestnut and acorn," Bioresource Technology, vol. 100, pp. 6639-6643, 2009.

[17] J. Rodier, B. Legube, N. Merlet, and R. Brunet, L'analyse de l'eau, DUNOD, Paris, France, 9th edition, 2009.

[18] P. Deshmukh, D. Peshwe, and S. Pathak, "FTIR and TGA analysis in relation with the $\%$ crystallinity of the $\mathrm{SiO}_{2}$ obtained by burning rice husk at various temperatures," $\mathrm{Ad}$ vanced Materials Research, vol. 585, pp. 77-81, 2012.

[19] P. Gebbie, "An operator's guide to water treatment coagulants," in Proceedings of the 31st Annual Qld Water Industry Workshop-Operations Skills University Central Queensland, pp. 14-20, Rockhampton, Australia, 2006.

[20] V. Patale and J. Pandya, "Mucilage extract of Cocciniaindica fruit as coagulant-flocculent for turbid water treatment," Asian Journal of Plant Science \& Research, vol. 2, no. 4, pp. 442-445, 2012.

[21] C. Tsamo, M. Assabe, J. Argue, and S. O. Ihimbru, "Discoloration of methylene blue and slaughter house wastewater using maize cob biochar produced using a constructed burning chamber: a comparative study," Scientific African, vol. 3, pp. 1-13, Article ID e00078, 2019.

[22] C. Tsamo, A. Paltahe, D. Fotio, T. A. Vincent, and W. F. Sales, "One-, two-, and three-parameter isotherms, kinetics, and thermodynamic evaluation of $\mathrm{Co}$ (II) removal from aqueous solution using dead neem leaves," International Journal of Chemical Engineering, vol. 2019, Article ID 6452672, 14 pages, 2019.

[23] B. S. Deshmukh, S. N. Pimpalkar, R. M. Rakhunde, and V. A. Joshi, "Evaluation performance of natural strychnospotatorum over the synthetic coagulant alum for the treatment of turbid water," International Journal of Innovative Research in Science, Engineering and Technology, vol. 2, no. 11, pp. 6183-6189, 2013.

[24] J. Sánchez-Martín, J. Beltrán-Heredia, and J. A. Peres, “Improvement of the flocculation process in water treatment by using moringa oleifera seeds extract," Brazilian Journal of Chemical Engineering, vol. 29, no. 3, pp. 495-502, 2012.

[25] Q. H. Malik, "Performance of alum and assorted coagulants in turbidity removal of muddy water," Applied Water Science, vol. 8, no. 40, pp. 2-4, 2018.

[26] M. A. Yukselen and J. Gregory, "The effect of rapid mixing on the break-up and re-formation of flocs," Journal of Chemical 
Technology and Biotechnology, vol. 79, no. 7, pp. 782-788, 2004.

[27] J. Gregory and J. Duan, "Hydrolyzing metal salts as coagulants," Pure and Applied Chemistry, vol. 73, no. 12, pp. 2017-2026, 2001. 